\title{
レーザー核融合ペレットの金属膜厚測定
}

吉田弘樹, 山取 真也*, 阪上 幸男

岐阜大学工学部電気電子工学科（广 501-1111 岐阜市柳戸 1-1）

\section{Accurate Metal Thickness Determination of a Pellet for Laser Fusion}

\author{
Hiroki YOSHIDA, Shinya YAMADORI, and Yukio SAKAGAMI \\ Department of Electrical and Electronics Engineering, Faculty of Engineering \\ Gifu University, 1-1 Yanagido, Gifu 501-1111
}

(Received October 1, 1997)

\begin{abstract}
Spectrophotometry for determining the metal thickness of a laser-fusion pellet is proposed. The technique, which uses $\mathrm{Ni}$ ion solution from $\mathrm{Ni}$-coated glass micro-balloon, is demonstrated within $\pm 5 \%$ error. Using this technique, a conventional quartz crystal monitor is calibrated for spherical pellets.
\end{abstract}

Key Words: Laser fusion, Pellet calibration, Determination of thin film thickness, Spectrophotometry

1.はじめに

レーザー核融合研究では, GMB (Glass Micro-Balloon), PMB (Plastic Micro-Balloon), フォームシェルを用いてお りそそれらに $\mathrm{Au}, \mathrm{Al}$ 等の金属をコートする場合が多い。ま た,イグニッションの達成には, レーザー照射の均一性向 上が重要である。筆者らは, その達成にはペレットの無接 点支持が有効と考え,ペレットにNi薄膜をコートして磁気 力で無接点支持する磁気懸架の研究を行っている1,2). し たがって, $\mathrm{Ni}$ の膜厚を測定する必要が生じた。

一般に, 膜厚測定として, 機械的方法 (触針), 質量測定 (天 びん, 水晶振動子), 電気的方法 (抵抗, うず電流, 容量), 電 子顕微鏡 (走査型, 透過型) , 光学的方法 (光吸収, 干渉, 偏 光, 変位), 分光光度分析 (吸光, 比色), レーザー顕微鏡 (干 渉, レンズ焦点検出), 放射線 (X線ラジオグラフィー, 蛍光 X線, 放射化分析, イオンプローブ), が上げられる.

レーザー核融合研究では, 金属薄膜計測として, 上で述 ベた水晶振動子, 走査型電子顕微鏡 ${ }^{3)}, X$ 線ラジオグラ フィー3), 光学的方法, 等が行わ机ている. 本論文では分光 光度分析 (吸光)が有用な方法であることを述べる．次に， 球状の Ni膜厚測定では水晶振動子の測定值を断面積と表 面積との比で換算せざるを得ず, 水晶振動子の較正に対し てもこの方法が有用な方法であることを述べる。

\section{2. $\mathrm{Ni}$ 薄膜コート}

今回,ペレットとしてGMBを, 金属薄膜としてNiを, 磁気 懸架に用いている. Fig.1は筆者らの抵抗加熱式真空蒸着
装置である，以下にこの装置を用いたNiコート GMB $(\mathrm{Ni}-$ $\mathrm{GMB})$ の製作について説明する。およそ10個のGMBを メッシュ (銅線 $0.24 \mathrm{~mm} \phi$, ピッチ $0.65 \mathrm{~mm})$ 製のかご $(20 \mathrm{~mm} \times$ $20 \mathrm{~mm}$, 高さ $12 \mathrm{~mm}$ ) に入れ,バイブレータで〜 $350 \mathrm{~Hz}$ の振動 を与える。この $\mathrm{GMB} の$ 数とバイブレータの振動周波数 は, GMBが良好に転がる值として実験的に決めた数值であ る。ここでは,バイブレータとして電磁スピーカーを用い る。 $\mathrm{Ni}(99.99 \%)$ を装置下部のタングステンボートに乗せ， $\mathrm{AC}$ 電流を〜120A流してNiを蒸発させる。このかごとタン

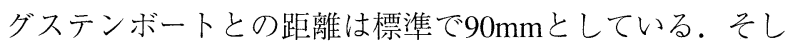
て, タングステンボードの上のシャッターを開き, 水晶振 動子式の成膜コントローラ(日本真空技術, CRTM-5000)で 監視しながら蒸着する。後に述べる水晶振動子の較正に 基づいて成膜コントローラの值が目標の膜厚の11倍にな るまで蒸着したら,シャッターを閉めて蒸着を終える．膜 厚70nmの蒸着をする場合, 蒸着時間は10分間程度である. なお, GMBとメッシュのかごは下地処理として,アセトン で5分間以上超音波洗浄を行い, 油脂及び油脂以外の付着物 を除去してから用いる。

\section{3. 膜厚測定}

3.1 吸光光度分析法による膜厚測定の原理

吸光光度分析は試料による光の吸収の割合を測定比較 して分析を行うものである。単色光が均質な媒質を通過 するとき, 入射光強度 $I_{0}$, 透過光強度 $I$, 媒質層の厚さ $l$, 媒質 中の光を吸収する成分の濃度 $c$, 吸光係数 $\varepsilon_{\lambda}$ とすると, Lambert-Beerの法則より吸光度Aは

*現在の所属 : 三菱電線工業株式会社

* Present address: Mitsubishi Cable Industries 


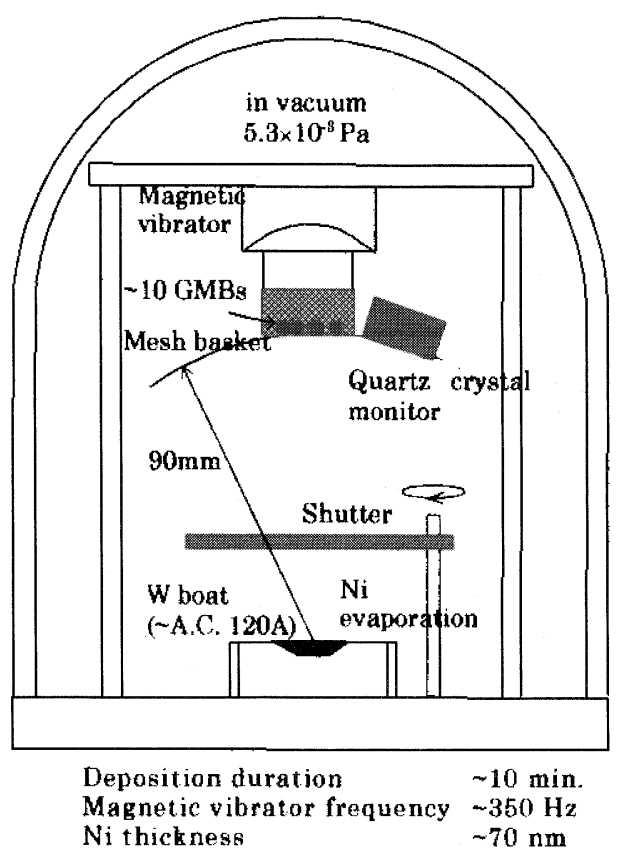

Fig.1 Resistance heating vacuum deposition system.

$$
A=\log \frac{I_{0}}{I}=-\log \frac{I}{I_{0}}=\varepsilon_{\lambda} l c
$$

となる. $\mathrm{Ni}$ の吸光光度分析では, 多くの有機発色試薬が知 られているが, そのうち $\mathrm{HON}=\mathrm{C}-\mathrm{C}=\mathrm{NOH}$ 基4)をもつ試薬 がもっとも多く用いられている。この基をもつジオキシ ム類はNiと反応して発色を示す. Niを溶かした液量をLと すると $\mathrm{Ni}$ の質量 $m$ は

$$
m=c \cdot L
$$

である。また, $\mathrm{GMB}$ の半径を $r_{\mathrm{p}}, \mathrm{Ni}$ の膜厚を $t, \mathrm{Ni}$ の密度を $\rho$ とすると，

$$
m=4 \pi r_{\mathrm{p}}^{2} t \rho
$$

となる。Eq. (1)-(3)より膜厚 $t$ は

$$
t=\frac{A L}{\varepsilon_{\lambda} l 4 \pi r_{\mathrm{p}}^{2} \rho}
$$

と求められる。したがって, $\varepsilon_{\lambda}$ を求めておき, 個々のNi$\mathrm{GMB} の A$ と $r_{\mathrm{p}}$ をE. (4)に与えることによってtを得る。また この式は,メッシュのかごに入れた同一ロットの GMB〜 10 個に関してAが $r_{\mathrm{p}}{ }^{2} に$ 比例するならば, そのロットの $\mathrm{Ni}$ の膜 厚がみな等しいことを意味している。この原理に基づい て, 以下に示す手順で実験をした。この時, 測定值の有効 桁数は2または3である.

\section{2 検量線の作成}

$1.0 \mathrm{mg}$ の Ni板 $(99.99 \%)$ を塩酸で溶かし, 水で希釈してNi 濃度 $0.10 \mathrm{mg} / \mathrm{m} \ell$ の溶液 $(\mathrm{A}) 10.0 \mathrm{~m} \ell$ を作った。この溶液 $(\mathrm{A})$ か

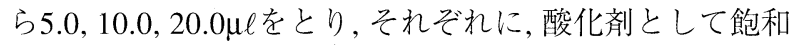

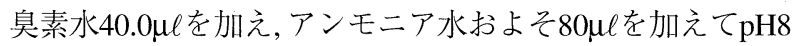
〜10にした。ささらに, ジメチルグリオキシム溶液 $40.0 \mu \ell を$
加えて発色させて溶液 (B)を作った。 これらを純水で希釈 して全容 $1.00 \mathrm{~m} \ell$ にることによって, Ni濃度 $0.50,1.0,2.0$ $\mu \mathrm{g} / \mathrm{m} \ell$ の溶液 $(\mathrm{C})$ を作った。これらを測定試料として, $l=$ $10.0 \mathrm{~mm}$ の分光光度計の標準ガラスセルに移した.このと き参照試料としては溶液 $(\mathrm{A})$ を用いずに溶液 $(\mathrm{B}) \sim(\mathrm{C})$ と 同じ手順で作った溶液, すなわち, 飽和臭素水 $40.0 \mu \ell$, アン モニア水およそ $80 \mu \ell$, ジメチルグリオキシム溶液 $40.0 \mu \ell$, に

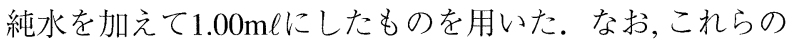
試薬を作ったあと10分以内に, 自記分光光度計 (日立, UV330)で吸光度を測定した。

$\mathrm{Ni}$ 濃度 $1.0 \mu \mathrm{g} / \mathrm{m} \ell$ の溶液 $(\mathrm{C})$ の波長に対する吸光度を測定 して得た吸収曲線をFig.2に示す。これより吸収極大波長 は445nmであることを確認した。この波長の吸光度は, 溶 液を作った後10分程度の時間内はほとんど変化しない5)。 残りの $\mathrm{Ni}$ 濃度の異なる 2 つ溶液 $(\mathrm{C})$ の吸光度も測定し, Fig.3に示す検量線を作成し, その傾きと $l=10.0 \mathrm{~mm}$ から吸 光係数 $\varepsilon_{445 \mathrm{~nm}}=25 \mu \ell /(\mu \mathrm{g} \cdot \mathrm{mm})$ と決定した.

\section{3 膜厚測定結果}

前述のように我々の真空蒸着装置では, 一度におよそ10 個のGMBをコートできる. 今回, 水晶振動子式成膜コント ローラーの值 $t^{\prime}$ が $8.00 \times 10^{2} \mathrm{~nm}$ と $6.20 \times 10^{2} \mathrm{~nm}$ になるまで蒸 着して, 異なる膜厚の 2 ロトを準備した。 また, あらかじ めGMBの半径を測定することで, コート後でもNi-GMBを 特定できるようにした。

各ロットそれぞれ9個のNi-GMBについて,それぞれ個別

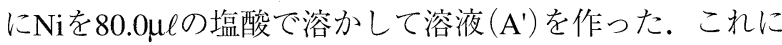
飽和臭素水 $40.0 \mu \ell$, アンモニア水扮よそ $80 \mu \ell$ を加えて $\mathrm{pH} 8$

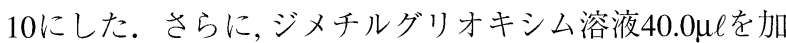
えて発色させ, 溶液 $\left(\mathrm{B}^{\prime}\right)$ を作った。 これに純水を加えて全 量で $1.00 \mathrm{~m} \ell$ の溶液 $\left(\mathrm{C}^{\prime}\right)$ を作り,これを測定試料とした。そ

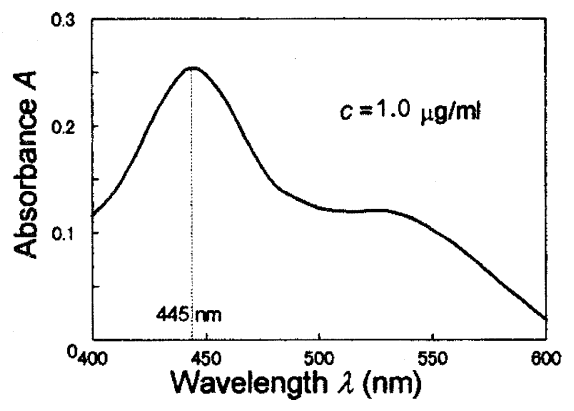

Fig.2 Absorption spectrum of the solution (C).

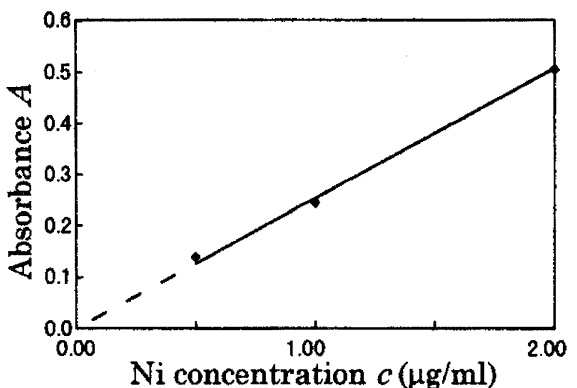

Fig.3 Calibration curve of the solutions (C). 


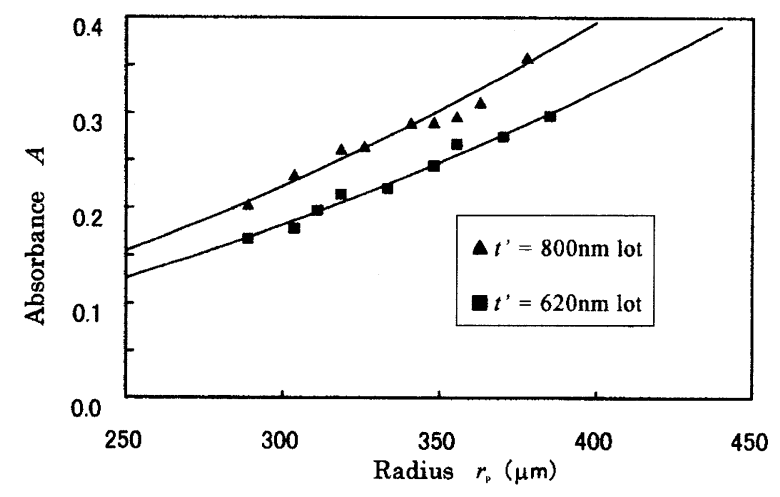

Fig.4 Measured dependence of $A$ on $r_{\mathrm{p}}$.

して, 溶液 $\left(\mathrm{A}^{\prime}\right)$ を用いずに溶液 $\left(\mathrm{B}^{\prime}\right) \sim\left(\mathrm{C}^{\prime}\right)$ と同じ手順で作っ た参照試料を用いて, 自記分光光度計で波長 $445 \mathrm{~nm}$ の吸光 度を測定した。その結果得た半径と吸光度との関係を Fig.4に示す。このときの吸光度は0.16 0.36であり, 前述 の検量線の測定範囲内にあった. 図中の実線は $r_{\mathrm{p}}{ }^{2}$ の実験 曲線であり，いずれのロットもAが $r_{\mathrm{p}}{ }^{2} に$ 比例していること が判る。すなわち、これは同一ロットの膜厚がみな等しく なることを示している.

それらのNi-GMBの半径とその吸光度, $l=10.0 \mathrm{~mm}, L=$ $1.00 \mathrm{~m} \ell$, 前述で得た $\varepsilon_{445 \mathrm{~nm}}=25 \mu \ell /(\mu \mathrm{g} \cdot \mathrm{mm})$ を Eq. (4)に与 え, 密度としてはNi板と同じ $\rho=8.85 \mathrm{~g} / \mathrm{cm}^{3}$ として得た膜厚 と半径との関係をFig.5に示す. 同一ロット内では, 半径に よらず膜厚は一定であり, $t^{\prime}=8.00 \times 10^{2} \mathrm{~nm}(800 \mathrm{~nm}$ lotと称 す)の膜厚は $87 \mathrm{~nm} て ゙, t^{\prime}=6.20 \times 10^{2} \mathrm{~nm}(620 \mathrm{~nm}$ lot 称す $)$ の 膜厚は $71 \mathrm{~nm}$ であった。この $87 \mathrm{~nm}$ と $71 \mathrm{~nm}$ の誤差は $\pm 5 \%$ 程 度であり,それはペレット半径, 液量, 吸光度の測定におい て生じたものである。

成膜コントローラの值が $8.00 \times 10^{2} \mathrm{~nm}$ のロットの NiGMBの断面を走査型電子顕微鏡 (日立, H-8100)によって観 察した。 それらの断面の一例をFig.6に示す。このNi-GMB の $\mathrm{Ni}$ の膜厚は90nmであり,前述の誤差の範囲で一致してい た。

\section{4. 水晶振動子式成膜コントローラの較正}

成膜コントローラの水晶振動子は平板であるがGMBは 球状である。すでに述べたように, 筆者らは成膜コント ローラの測定值をGMBの断面積と表面積の比で換算して きた。ここで, 上記の膜厚測定結果を用いて成膜コント

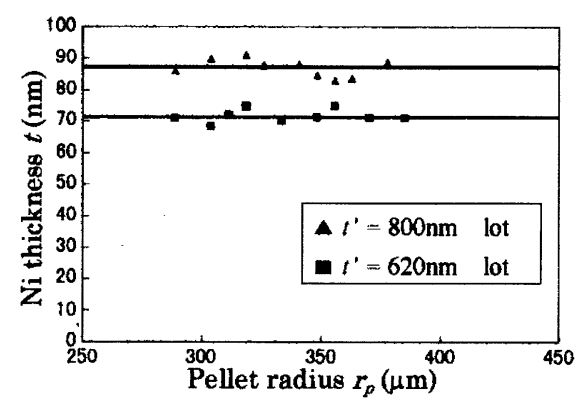

Fig.5 The determined thickness by spectrophotometry.

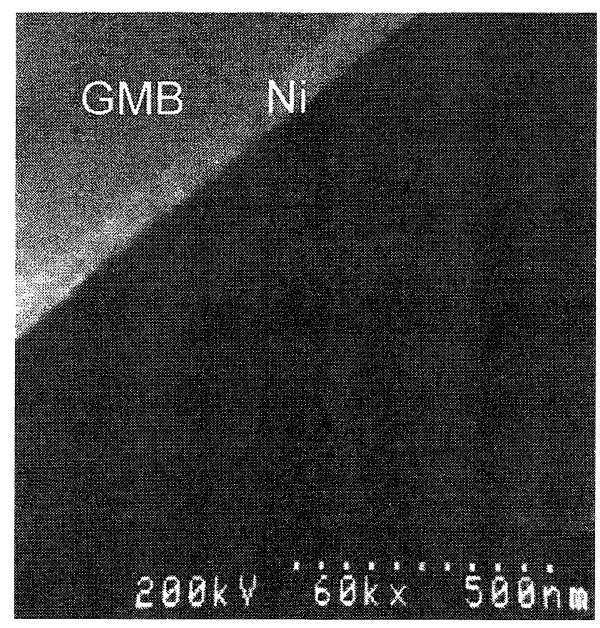

Fig.6 Cross sectional view of a Ni-GMB by a SEM.

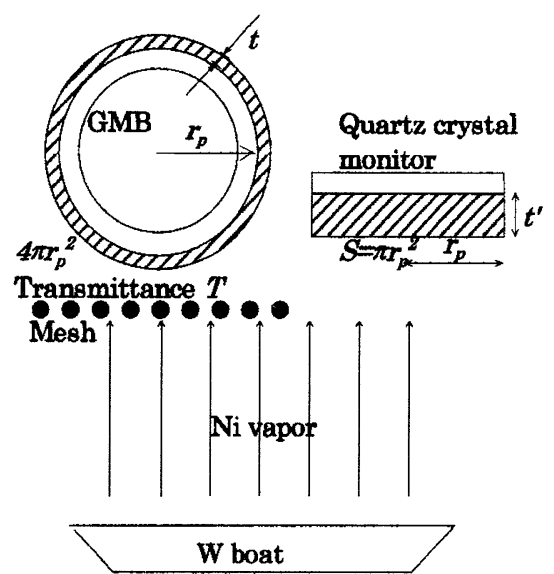

Fig.7 Deposition model.

ローラを較正した。

水晶振動子とメッシュ上のGMBへの蒸着のモデルが提 案されている、筆者らがそのモデルにメッシュの透過率 を考慮をしたものをFig.7に示す。バイブレータによって GMBをメッシュ上でランダムに振動させながら蒸着す る.そのGMBの断面積を $S$, メッシュの透過率を $T$ とする と, $\mathrm{Ni}$ の膜厚 $t$ と水晶振動子の $\mathrm{Ni}$ の膜厚 $t$ 'の関係は

$$
4 \pi r_{\mathrm{p}}^{2}=T S t^{\prime}
$$

となる。断面積 $S$ は

$$
S=\pi r_{\mathrm{p}}^{2}
$$

であるから,これをEq. (5)に代入して

$$
4 \pi r_{\mathrm{p}}^{2} t=\pi r_{\mathrm{p}}^{2} t^{\prime} \cdot T
$$

となる。また,メッシュの透過率を $44 \%$ と与えると, $t$ と $t^{\prime}$ の関係は

$$
\frac{t}{t^{\prime}}=0.11
$$

である。これより $t^{\prime}=8.00 \times 10^{2} \mathrm{~nm}$ のとき膜厚 $t=88 \mathrm{~nm}, t^{\prime}$ $=6.20 \times 10^{2} \mathrm{~nm}$ のとき $t=68 \mathrm{~nm}$ を得た。 


\section{5. まとめ}

今回, 吸光光度分析法を用いてNi-GMBから直接にNiの 膜厚を測定し，この方法が $\mathrm{Ni}$ の膜厚測定法の一つとして有 用な方法であることを示した。レーザー核融合の分野で 用いられている他の金属, たとえば, Auはジメチルアミノ チオベンゾフェノンと反応して, Alはオキシンと反応し て,発色することが知られており6),この方法はこれらの金 属薄膜の測定にも適用できると考えられる．次に,この方 法を用いて水晶振動子式成膜コントローラの較正を行い, この方法が球状の膜厚測定に対しても有用な方法である ことを示した。

\section{謝 辞}

本研究は, 文部省科学研究費基盤 $(\mathrm{C})$, および大阪大学
レーザー研究センターとの共同研究費の交付,により遂行 した. SEMによる観測は, 本学機器分析センターの施設利 用よって実施した.

\section{参考文献}

1) Y. Sakagami, H. Yoshida, T. Mizutani, S. Miyagawa, M. Sekimura, and K. Yasufuku: Int. Conf. Laser Inter. and Related Plasma Phenomena (AIP 1996) p.119.

2) H. Yoshida, Y. Sakagami, K. Yasufuku, S. Yamadori, and T. Konishi: Proc. of the 1996 Int. Conf. on Plasma Phys. (The Japan Soc. of Plasma Sci. and Nucl. Fusion Research 1996) p.1798.

3) Inst. of Laser Eng.: Annual Progress Report on Laser Fusion Program Sep.1977-Aug.1978 ILE-APR-78(Inst. of Laser Eng., 1978) p.129.

4) 無機応用比色分析編集員会編：無機応用比色分析(共立出版, 1975) p.4.

5) A. M. Mitchell and M. G. Mellon: Ind. Eng. Chem. 17 (1945) 380.

6) 大西 実, 束原 倣: 吸光光度法一無機編 (共立出版,1983). 